\title{
СОВРЕМЕННЫЕ ОБРАЗОВАТЕЛЬНЫЕ ТЕХНОЛОГИИ, КАК ЭФФЕКТИВНОЕ СРЕДСТВО ПОВЫШЕНИЯ КАЧЕСТВА ОБРАЗОВАНИЯ В КОНТЕКСТЕ ЭКОНОМИЧЕСКОЙ БЕЗОПАСНОСТИ РОССИЙСКОЙ ФЕДЕРАЦИИ
}

\author{
(c) 2020 Соколова Екатерина Иосифовна \\ кандидат филологический наук, доцент, кафедра иностранных языков № 3 \\ Российский экономический университет им. Г.В. Плеханова, Россия, Москва \\ E-mail:kafmkk@mail.ru
}

В статье автора анализируется вопрос воздействия современных образовательных технологий на качество образовательного процесса в аспекте экономической безопасности Российской Федерации. Объектом исследования выступило качество образования в Российской Федерации, а предметом современные образовательные технологии в контексте возможных негативных последствий в сфере экономической безопасности. Теоретическое и методологическое значение исследования заключены в развитии инструментария, способствующего повышению качества образовательного процесса и одновременно эффективности его протекания. Практическое значение исследования определяется способствованию внедрения современных образовательных технологий при условии сохранения экономической безопасности Российской Федерации.

Ключевые слова: Образование, технологии, эффект, средство, современность, качество, контекст, экономическая безопасность, Российская Федерация.

В условиях высокой и эффективной конкуренции на том или ином рынке значительную актуальность приобретают вопросы использования современного инструментария с целью приобретения значимых конкурентных преимуществ как в текущей, так и стратегической перспективах.

На рынке Российской Федерации в условиях мирового финансового кризиса, формирующего значительную неопределенность взаимодействия субъектов, указанный тезис становится весьма актуальным, в первую очередь, для рынков, связанных со здравоохранением, образованием и материальным потреблением ценностей. Так, по данным рейтингового агентства «Эксперт-РА» [8] в Российской Федерации уровень конкуренции на рынке образования в 2019 году составил более 56 единиц из 100 возможных с положительной динамикой, относительно 2018 года, в 1,16 раза (рис. 1). В целом же уровень конкуренции, за обозначенный период времени, вырос более чем в 1,46 раза.

Следствием картины, отраженной на рисунке 1 , для сохранения и усиления текущих конкурентных позиций, является необходимость изменения параметров функционирования субъектов на обозначенном рынке.

По данным компании Ernst\&Young одним из ключевых параметров функционирования обра- зовательных учреждений на рынке Российской Федерации является качество образования, уровень которого считают существенным 95,89\% из опрошенных в 2020 году респондентов [9].

Усредненные показатели качества образования в Российской Федерации, сгруппированные по всем учебным заведениям, за последние пять лет приведены на рисунке 2.

Из рисунка 2 можно увидеть следующее:

- процессу изменения анализируемого показателя в 2015-2019 годах, с вероятностью 97,63\% свойственен линейный характер (это можно увидеть, обратив внимание на линейное уравнение, расположенное чуть выше кривой);

- динамику изменения в целом можно охарактеризовать как отрицательную (значение анализируемого показателя за истекший период сократилось с 57,38 ед. до 51,98 ед. или более чем в 1,1 раза);

- ритмичность изменения качества образования можно оценить как среднюю, без присутствия существенных лагов и неоднородностей (анализируемая кривая характеризуется двумя относительными восходящими и одним нисходящим пиком);

- для всех без исключения учебных заведений в Российской Федерации является актуальным вопрос повышения качества образования в краткосрочной, среднесрочной и долгосрочной 


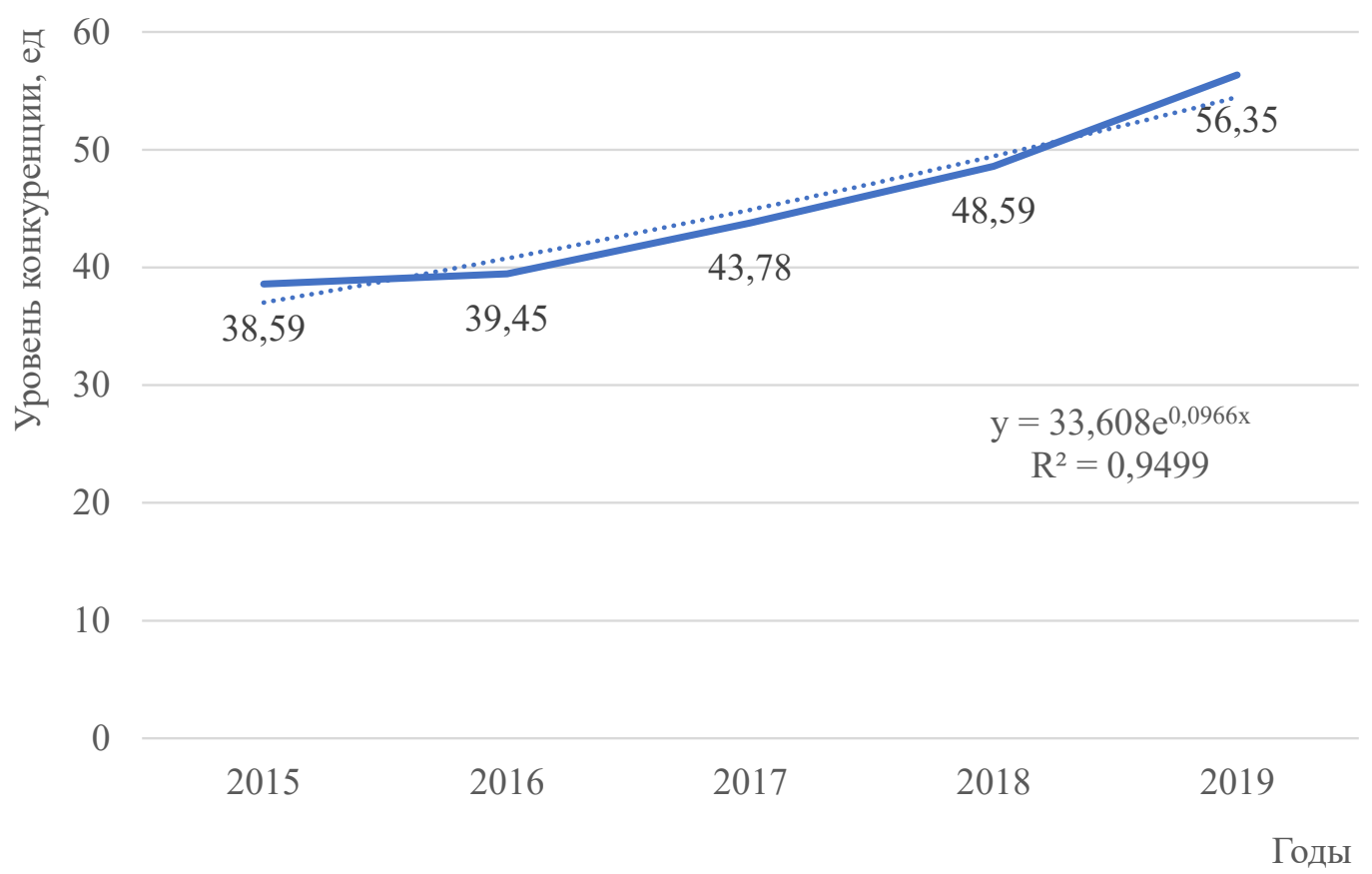

Рис. 1. Уровни конкуренции на рынке образования в Российской Федерации в 2015-2019 годах

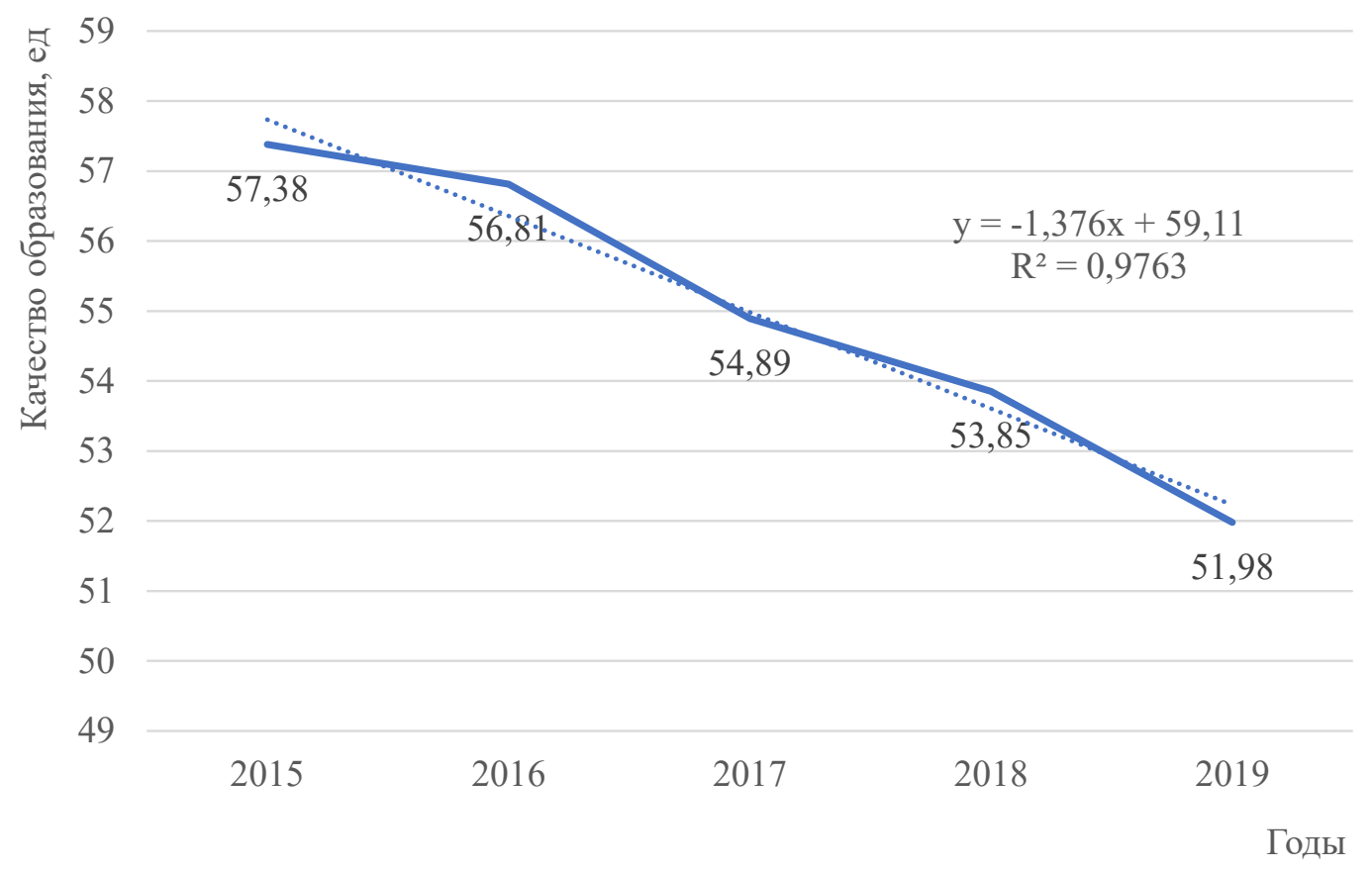

Рuс. 2. Усредненные показатели качества образования в Российской Федерации в 2015-2019 годах 
перспективах.

По мнению многих авторитетных ученых [7, с. 375] одним из эффективных, как с теоретической, так и практической точек зрения инструментов повышения качества образования [1, 3] в мире и в Российской Федерации в частности, в 2020 году и далее является применение современных образовательных инструментов и технологий [6, с. 53]. Состав и содержание данных технологий, возможных для использования в качестве инструмента повышения качества образования в Российской Федерации приведен в таблице 1. Следовательно, исходя из содержания таблицы 1, можно сделать вывод о возможном использовании пяти видов инструментов для повышения качества образования [2, с. 65] в Российской Федерации. При этом перечень инструментов всегда может быть расширен за счет задействования группы «прочие», носящей открытый характер.

Исходя из того, что указанные в таблице 1 виды образовательных технологий могут, в том числе, ввиду влияния на процесс образования, негативно отразиться на экономической безопасности Российской Федерации $[4,5]$, рассмотрим данный вопрос более подробно.

На рисунке 3 приведен усредненный уровень вероятностного влияния современных образовательных технологий, возможных для использования в качестве инструмента повышения качества образования, на экономическую безопасность Российской Федерации на начало 2020 года $[8,9]$.

Как можно увидеть, приведенные данные свидетельствуют о следующем:

- наибольшее негативное влияние на экономическую безопасность Российской Федерации может оказать информационный инструментарий (средний уровень воздействия порядка 29,85\% из 100 возможных);

- далее следует организационный инструментарий со средним уровнем негативного воздействия на экономическую безопасность Российской Федерации порядка 27,34\%;

- чуть ниже указанных технологий расположился нормативно-правовой инструментарий (средний уровень воздействия порядка 19,68\% из 100 возможных);

- предпоследний вид образовательных технологий, содержащий прикладной инструментарий, оказывает негативное влияние на экономическую безопасность Российской Федерации в районе 15,12\% из 100 возможных;

- завершает перечень образовательных технологий прочий инструментарий (средний уровень воздействия чуть более $8 \%$ ).

Таким образом, можно сделать вывод, что ввиду значительного роста уровня конкуренции на рынке образования в Российской Федерации за последние пять лет существенную актуальность приобретают вопросы изменения параметров функционирования субъектов, связанных, в первую очередь, с качеством образовательного процесса.

Таблица 1. Состав и содержание современных образовательных технологий, возможных для использования в качестве инструмента повышения качества образования в Российской Федерации в краткосрочной, среднесрочной и долгосрочной перспективах

\begin{tabular}{|c|c|c|}
\hline $\begin{array}{c}\text { Вид } \\
\text { технологии }\end{array}$ & $\begin{array}{l}\text { Содержание } \\
\text { технологии }\end{array}$ & $\begin{array}{c}\text { Влияние на качество } \\
\text { образования }\end{array}$ \\
\hline $\begin{array}{l}\text { Информационный } \\
\text { инструментарий }\end{array}$ & $\begin{array}{l}\text { Применение передовых программных пакетов и } \\
\text { продуктов, способствующих оптимизации процесса } \\
\text { образования в Российской Федерации }\end{array}$ & $\begin{array}{l}\text { В целом можно оценить } \\
\text { как высокое }\end{array}$ \\
\hline $\begin{array}{l}\text { Организационный } \\
\text { инструментарий }\end{array}$ & $\begin{array}{l}\text { Применение передовых организационных методик и } \\
\text { наработок, способствующих оптимизации процесса } \\
\text { образования в Российской Федерации }\end{array}$ & $\begin{array}{l}\text { В целом можно оценить } \\
\text { как высокое }\end{array}$ \\
\hline $\begin{array}{l}\text { Нормативно-правовой } \\
\text { инструментарий }\end{array}$ & $\begin{array}{l}\text { Модернизация нормативно-правовой составляющей } \\
\text { обучения, способствующей оптимизации процесса } \\
\text { образования в Российской Федерации }\end{array}$ & $\begin{array}{l}\text { В целом можно оценить } \\
\text { как среднее }\end{array}$ \\
\hline $\begin{array}{l}\text { Прикладной инструмен- } \\
\text { тарий }\end{array}$ & $\begin{array}{l}\text { Применение прикладных (в том числе вербальных, } \\
\text { психологических) инструментов, способствующих } \\
\text { оптимизации процесса образования в Российской } \\
\text { Федерации }\end{array}$ & $\begin{array}{l}\text { В целом можно оценить } \\
\text { как среднее }\end{array}$ \\
\hline Прочий инструментарий & $\begin{array}{l}\text { Применение прочих инструментов (включая, нетра- } \\
\text { диционных), способствующих оптимизации процес- } \\
\text { са образования в Российской Федерации }\end{array}$ & $\begin{array}{l}\text { В целом можно оценить } \\
\text { как низкое }\end{array}$ \\
\hline
\end{tabular}




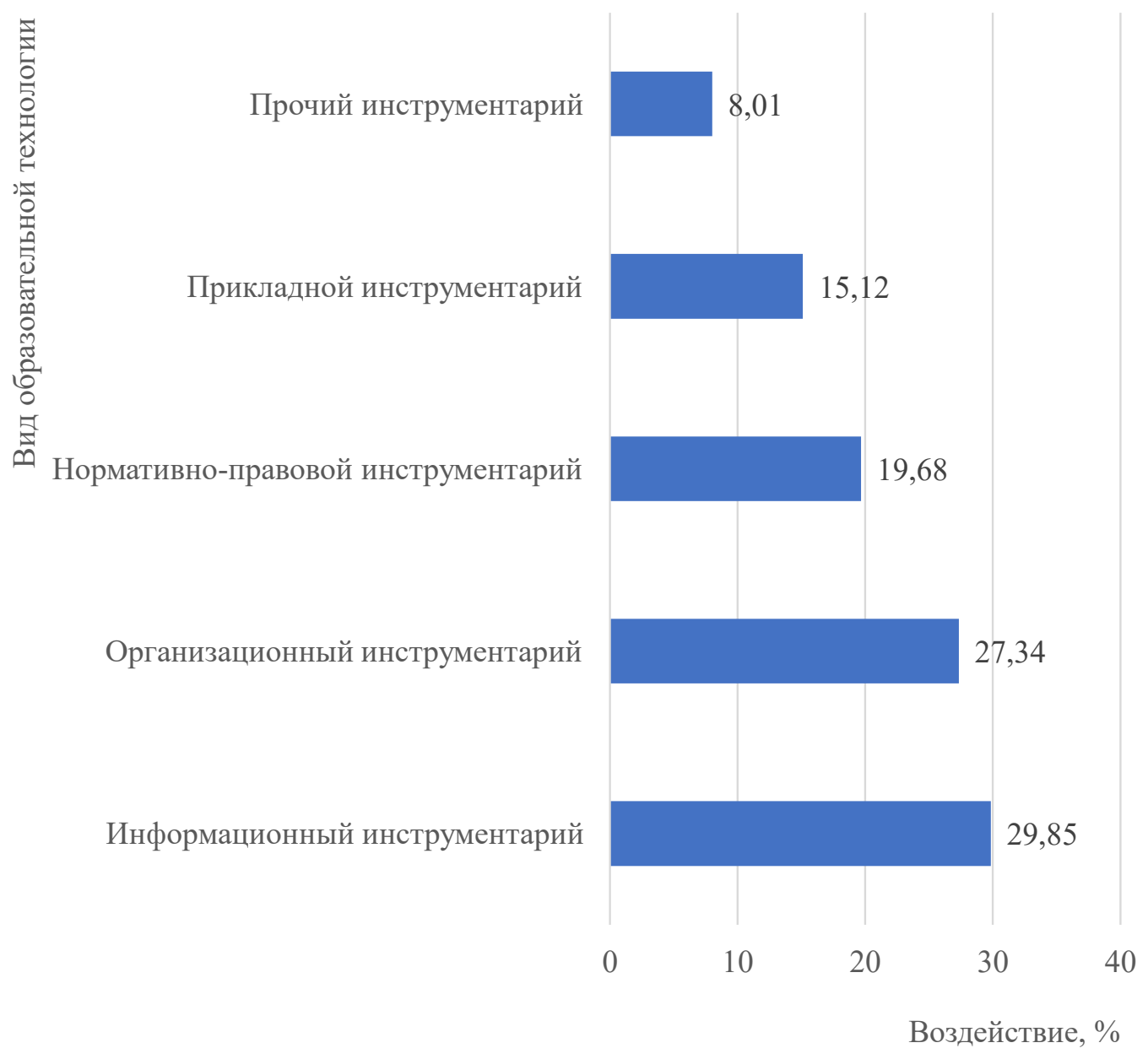

Puc. 3. Усредненный уровень вероятностного влияния современных образовательных технологий, возможных для использования в качестве инструмента повышения качества образования на экономическую безопасность Российской Федерации на начало 2020 года

На основе изучения специализированных данных в целом можно отметить относительное снижение качества образования в Российской Федерации, вызванное, в том числе недостаточно активным использованием современных образовательных технологий.

Для разрешения сложившейся ситуации в Российской Федерации целесообразно использовать следующие образовательные технологии, способствующие повышению качества образо- вания: информационный инструментарий, организационный инструментарий, нормативноправовой инструментарий, прикладной и прочий инструментарий.

Наименее негативное влияние на экономическую безопасность Российской Федерации оказывают три последние образовательные технологии, связанные с нормативно-правовым, прикладным и прочим инструментарием.

\section{Библиографический список}

1. Бауржан А.Б. и другие Современные образовательные технологии в мировом учебно-воспитательном пространстве / А.Б. Бауржан, Ж.Ж. Чинпулатов, А.К. Жумабаев, У.П. Суюнжанова, Х.И. Бейсенов // Педагогика высшей школы - Казань: Изд-во: ООО «Издательство Молодой ученый», 2017. - № 1. - С. 4-7.

2. Козлова О.А. Использование электронных образовательных ресурсов как средство повышения качества образования / О.А. Козлова // Информационно-коммуникационные технологии в педагогическом образовании - Новокузнецк: Изд-во: «Кузбасская государственная педагогическая академия», 2017. - № 2.C. 64-68. 
3. Лорени В.В. Современные образовательные технологии и их возможности для формирования творческой личности школьника / В.В. Лоренц // Инновационные технологии в науке и образовании - Чебоксары: Изд-во: ООО «Центр научного сотрудничества «Интерактив плюс», 2017. - № 1.- С. 126-129.

4. Николаева Е.А., Григорьева И.В. и др. К аспектам влияния оценки эффективности деятельности профессорскопреподавательского состава высшего учебного заведения на укрепление экономической безопасности Российской Федерации / Е.А. Николаева, И.В. Григорьева, И.С. Казимирова, Е.И. Соколова // Экономические науки - Москва: Изд-во: ООО «24-Принт», 2019. - № 3. - С. 62-67.

5. Слободяник А.П. Понятие и сущность экономической безопасности высшего учебного заведения / А. П. Слободяник // Наука через призму времени - Самара: Изд-во: ИП «Фаритов Анатолий Тависович», 2018.№ 1.- С. 101-104.

6. Шахова Н.И. Использование современных образовательных технологий в решении проблем активизации творческой и познавательной деятельности детей / Н.И. Шахова // Проблемы современной науки - Ставрополь: Изд-во: «Центр научного знания «Логос», 2017.- № 27.- С. 50-53.

7. Drexler, W. (2010). The Networked Student Model for Construction of Personal Learning Environments: Balancing Teacher Control and Student Autonomy. Australasian Journal of Educational Technology, 26(3), pp. 369-385.

8. Компания «Эксперт РА» [Электронный ресурс]: аналитические материалы - Официальный сайт компании «Эксперт РА», 2020.- Режим доступа: https://raexpert.ru

9. Компания «Ernst\&Young» [Электронный ресурс]: аналитические материалы - Официальный сайт компании «Ernst\&Young», 2020.- Режим доступа: https://www.ey.com/ru 